James Madison University JMU Scholarly Commons

Libraries

Libraries \& Educational Technologies

$11-21-2016$

\title{
Scalable Equals Asynchronous and Asynchronous Equals Boring. Or Does It?
}

Liz Thompson

James Madison University, lizthompson2728@gmail.com

Howard Carrier

James Madison University

Follow this and additional works at: http://commons.lib.jmu.edu/letfspubs

Part of the Library and Information Science Commons, and the Online and Distance Education Commons

\section{Recommended Citation}

Thompson, L. and Carrier, H.S. (2016). Scalable equals asynchronous and asynchronous equals boring. Or does it? Internet Reference Services Quarterly, 21(3-4), 81-92. doi:10.1080/10875301.2016.1241202

This Article is brought to you for free and open access by the Libraries \& Educational Technologies at JMU Scholarly Commons. It has been accepted for inclusion in Libraries by an authorized administrator of JMU Scholarly Commons. For more information, please contact dc_admin@jmu.edu. 


\title{
Taking a first step to develop scalable, asynchronous library instruction
}

\author{
Liz Thompson \\ Instruction and Educational Resources Coordinator, Assistant Professor, James Madison University, \\ http://orcid.org/0000-0003-4382-5136
}

Howard S. Carrier

Social Sciences Librarian, Assistant Professor, James Madison University, http://orcid.org/0000-0003-0978-2232

\begin{abstract}
This paper reports on recent work to introduce a model of scalable, asynchronous library instruction into the First Year Writing program at James Madison University, inspired by the premise: Scalable equals asynchronous. And asynchronous equals boring. Or does it? The authors describe how a small team from Libraries \& Educational Technologies at James Madison University planned and built an asynchronous, modular tutorial series, primarily designed to motivate students to engage with the library instruction contained within it. Information literacy instruction was provided using a tool called "Guide on the Side” and employed short scenario videos and additional content, followed by activities and assessment, in order to improve student outcomes and engagement. In this foundational program, the new and engaging asynchronous materials became the first step of a library instruction model that aimed to reach as many students as possible, while still being sustained by one librarian.
\end{abstract}




\section{Introduction}

About James Madison University and the First Year Writing Program:

James Madison University (JMU) is a public university located in Harrisonburg, in Virginia’s Shenandoah Valley. In 2015, JMU recorded a total enrollment of 20,211 students, which included a first year enrollment of 4,783 (State Council of Higher Education for Virginia, 2016). JMU’s First Year Writing Program is housed within the School of Writing, Rhetoric, and Technical Communication (WRTC), and offers more than 60 sections of the foundational first-year writing course, WRTC 103, to an excess of 1,000 students per semester. The First Year Writing Program is supported by one librarian from JMU's Libraries \& Educational Technologies (LET), who, in recent years, has typically provided 20 oneshot, face-to-face library instruction sessions each semester to the program’s WRTC 103 classes.

Moving from face-to-face instruction to asynchronous instruction for WRTC 103:

In the spring of 2015 the WRTC liaison librarian agreed to become the librarian-in-residence in JMU’s University Writing Center (UWC) for the 2015/16 academic year, and hence the prospect of teaching twenty, individual WRTC 103 sessions became unsustainable. At this time, the WRTC liaison librarian and LET's Library Instruction Specialist formed a small instructional design team. As part of the planning process, the design team consulted with an LET colleague, the Social Sciences librarian, who had past experience in creating asynchronous library instruction materials for distance learning classes, and who raised questions about the facility of asynchronous materials to motivate students to engage with library instruction. The method described by the Social Sciences librarian was one of taking complete, face-to-face library instruction sessions, transcribing the content of those sessions, and then recording the instruction in the format of a screen capture video by means of Camtasia or other suitable software, and subsequently distributing the resultant videos to students via the learning management system (Canvas). The asynchronous instruction could also be supplemented with quizzes administered via survey software such as Qualtrics, or linked assignments within the learning management system. The Social Sciences librarian proffered the opinion that this method had worked well for graduate classes and advanced undergraduate classes, but that the method struggled to capture the attention of students enrolled in first year classes. The method provided little motivation for lower-level undergraduates to actually watch the videos, and hence could prove ineffective in engaging first year students with library instruction.

At this juncture, it is useful to review existing literature examining the motivational qualities of asynchronous library instruction, and the effectiveness of tools for delivering such instruction, whereupon this paper will then report on the methodology adopted for teaching WRTC 103 classes during 2015, and the results of that work. 


\section{Review of Literature}

Is asynchronous library instruction boring?

A wider question here is: what factors can make library instruction boring? This question was examined in some detail, in the specific context of library instruction for first year students by Dennis \& Dees (2015). Early in their research, Dennis \& Dees presented a hypothesis about the causes of student boredom with library instruction: "Librarians originally felt that students may not have been bored with library instruction in the classic sense, but perhaps something else: overwhelmed with information [or] forced into learning,” (Dennis \& Dees, 2015, p.2). Using course evaluation and session evaluation data from students enrolled in an elective, first year class, the researchers compared data from 2012 and 2013 with data from 2014, during which time the librarians providing the instruction had moved the venue for instruction from physical "tours” to virtual instruction uploaded to Youtube(Dennis \& Dees, 2015, p. 7). While the move to virtual instruction did not diminish the students' ability to find materials (as assessed by quizzes), the virtual instruction, coupled with related activities (such as students taking "selfies” with the book they had found in the stacks), resulted in the number of students reporting boredom with library instruction declining from 62 to 23 (Dennis \& Dees, 2015, pp.7-8).

If a transition to virtual library instruction, supported by activities, has the potential to overcome boredom in students, what other possibilities exist in the asynchronous learning environment? How can a combination of pedagogy and technology be used to better engage students with library instruction? Gustavson et al (2011) reported on the development of asynchronous library instruction at East Carolina University, in response to a problem identified during student assessment exercises, "East Carolina students need[ed] more information literacy instruction than could be provided in a one-shot class" (Gustavson et al, 2011, p. 726). The question of scalability is highly relevant; the fact that the librarians at East Carolina University decided upon an asynchronous solution to this problem, instead of simply offering multi-sessional library instruction as opposed to one-shot instruction, may be seen to reflect the asynchronous model's ability to provide instruction without further encumbering librarians, or consuming more scheduled class time. The model described by Gustavson et al was somewhat in keeping with that described by the Social Sciences librarian at JMU: the chosen tool was Camtasia (Gustavson et al, 2011, p. 725), and the librarians attempted to cover many of the elements found in traditional, face-to-face library instruction within the video tutorials (Gustavson et al, 2011, p. 739). In order to make the tutorials engaging, the librarians specifically planned and produced the tutorials to have a "modern feel," utilizing the voice of a younger member of staff for the tutorials' narration, with the hope that this would better engage a young, student audience (Gustavson et al, 2011, passim). In terms of improving information 
literacy, the librarians acknowledged that results were mixed, “The results indicated students had difficulty understanding the use of Boolean operators, the identification of credible sources, citations and plagiarism, and the actual process of retrieving books from the library's collection” (Gustavson et al, 2011, p. 740). Another, highly informative aspect to the work of Gustavson et al was the acknowledged difficulty in dealing with the assessment element of the chosen asynchronous model. The chosen tools for recording and analyzing data (student responses to two quizzes linked to the library instruction) were found wanting (the tools used were Google Docs and Excel) (Gustavson et al, 2011, p. 739). The librarians reported a "major challenge" in grading the quizzes and collecting data, which may indicate a very time-consuming process within this chosen model of asynchronous delivery of library instruction (Gustavson et al, 2011, p. 740).

Is there a tool which allows for the distribution of asynchronous library instruction, and which would better facilitate easy collection of student responses? The design team at LET believed that “Guide on the Side” might provide a solution. Mikkelsen \& McMunn-Tetangco (2014) reported on this “Open source tutorial software developed at the University of Arizona” (Mikkelsen \& McMunn-Tetangco 2014, p.272). In terms of student engagement with library instruction, the authors noted the "highly interactive" nature of the software (Mikkelsen \& McMunn-Tetangco 2014, p.272). Another positive aspect to the software, as recorded by Mikkelsen \& McMunn-Tetangco, was its facility to include quizzes; the authors also considered expediency in terms of the time involved in creating the interactive tutorials, determining that the initial creation of the tutorials took longer than making simple, screen-capture tutorials, but that once created, the interactive tutorials were quicker to edit (Mikkelsen \& McMunn-Tetangco 2014, passim).

\section{Methodology}

The design team sought approval from JMU's Institutional Review Board before commencing work on the project. Approval was granted, protocol \#16-0119.

During the summer of 2015, the instructional design team planned, created, and distributed a set of tutorials to provide asynchronous information literacy instruction to first year writing classes. The chosen tool for providing the asynchronous instruction was “Guide on the Side” (GotS), an open-source program created and distributed by the University of Arizona.

Project analysis and design

The instructional design team used the ADDIE model as a framework for the first year writing tutorial project. ADDIE is an acronym that stands for Analyze, Design, Develop, Implement, and 
Evaluate, and this approach has been a popular model for the instructional design process for many years (Branch, 2008). The small instructional design team analyzed syllabi and assignments to identify information literacy topics common across sections of WRTC 103 and found three recurring themes: Topic selection, searching for information, and citing sources. Having identified three global topics, the team mapped each topic to both the General Education Writing Learning Objectives (2016) and ACRL Information Literacy Frameworks (2016) and wrote one specific learning outcome for each tutorial (see Table 1).

(Table 1. Tutorial student learning outcomes)

\begin{tabular}{|l|l|l|l|}
\hline Tutorial titles & $\begin{array}{l}\text { First-Year Writing } \\
\text { Learning Objectives (2016) }\end{array}$ & $\begin{array}{l}\text { ACRL } \\
\text { Frameworks } \\
\mathbf{( 2 0 1 6 )}\end{array}$ & $\begin{array}{l}\text { Tutorial Learning } \\
\text { Outcomes } \\
\text { "Students will ... }\end{array}$ \\
\hline Topic selection & $\begin{array}{l}\text { "Research ... as part of the } \\
\text { series of steps in the writing } \\
\text { process" }\end{array}$ & $\begin{array}{l}\text { "Research as } \\
\text { inquiry" }\end{array}$ & $\begin{array}{l}\text {.. determine an appropriate } \\
\text { scope of investigation for } \\
\text { different genres." }\end{array}$ \\
\hline Searching for & $\begin{array}{l}\text { "Analyze and evaluate texts } \\
\text { to identify their ... credible } \\
\text { elements" }\end{array}$ & "Scholarship as a \\
conversation" & $\begin{array}{l}\text {.. evaluate different } \\
\text { information formats for } \\
\text { credibility and will } \\
\text { recognize the role of } \\
\text { scholarly sources." }\end{array}$ \\
\hline Citing sources & $\begin{array}{l}\text { "Effectively incorporate and } \\
\text { document appropriate sources }\end{array}$ & $\begin{array}{l}\text { "Information has } \\
\text { value" }\end{array}$ & $\begin{array}{l}\text {.. give credit to the original } \\
\text { ideas of others through } \\
\text { proper attribution and } \\
\text { citation." }\end{array}$ \\
\hline
\end{tabular}

At this point in the process, the instructional design team transitioned from analyzing past instruction session materials and student learning outcomes to thinking about how to translate the content and student needs into an asynchronous instruction environment. The first step in the design process was to identify the most critical attributes to tutorial success. The design team wanted to maintain the dynamic student engagement encouraged in the face-to-face classroom environment. These dynamic, active learning characteristics are mirrored in Keller's (2010) description of the ARCS model of motivational 
design, so the instructional design team made a conscious decision to build the tutorials with student motivation and learning habits in mind.

The ARCS model focuses on developing a systems approach to motivational design in four key areas affecting student motivation: Attention, Relevance, Confidence, and Satisfaction (Keller, 2010). Attention-getting tactics used throughout the tutorials include creating a story through conversational exchanges between a student and a librarian and alternating the video placement with activities. To maintain students' attention, the design team created one to two minute videos and limited tutorial length to no more than fifteen minutes each. The design team established relevance through the conversation in the video exchanges. Also by creating tutorials with easy navigation, students that revisit the tutorials could easily jump right to the relevant content. Students could practice and gain confidence in their research skills by following the guided activities. The step-by-step process of working through the tutorials included formative multiple choice questions, giving students an opportunity to check their understanding and build their confidence in a non-punitive environment. Keeping the tutorials short, making the navigation within the tutorials easy, and providing immediate feedback to the formative activities are examples of the design elements that impact student satisfaction.

As the planning for the tutorials evolved, the instructional design team was forced to make decisions about which educational technologies were the most appropriate for this project. The design team wanted an engaging story to connect the viewers to the content but did not have the time to record full action videos. Instead, the team compromised by writing scripts and recording the audio conversations and then used still images from a photo shoot to create the final videos in Camtasia. In the videos, the WRTC liaison librarian and an undergraduate student had conversations based on actual student questions and common 'sticking points'. While the video conversations create a story arc which give the tutorial series a natural linear progression, each tutorial is designed to stand alone, giving faculty the flexibility to use one tutorial or multiple tutorials in any order based on their course needs.

\section{Tutorial creation}

The tutorials were designed to replicate the classroom instruction activity where students practice using online library resources. To do this asynchronously, students would have to be able to move seamlessly between the instructional content designed for the tutorials and the library's website, so the design team used GotS’s facility to create a dynamic asynchronous environment. Several people in LET's Digital Services department collaborated to host and test the GotS application on a JMU server. Since the application was hosted on a JMU server, system security was critical and students had to use their JMU credentials to access the tutorials. 
Each tutorial was created using the GotS system, and students followed the GotS prompts on the left side of the screen to watch the videos (see Image 1) which were embedded in several LibGuides (SpringShare).

(Image 1. Tutorial video)

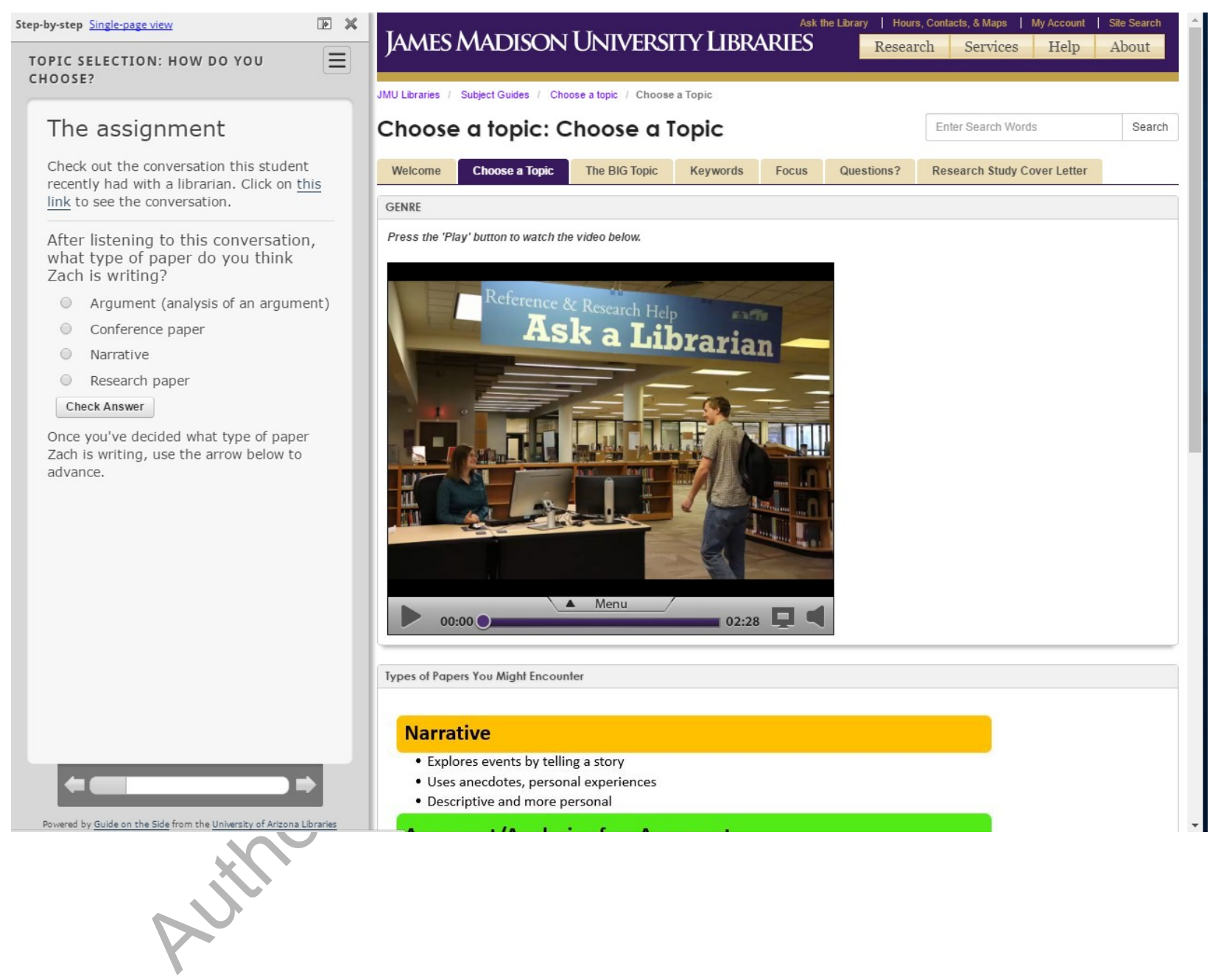


Students also completed activities on the LET's website (see Image 2) and received immediate formative feedback to their multiple choice answers (see Image 3).

(Image 2. Tutorial live library website)

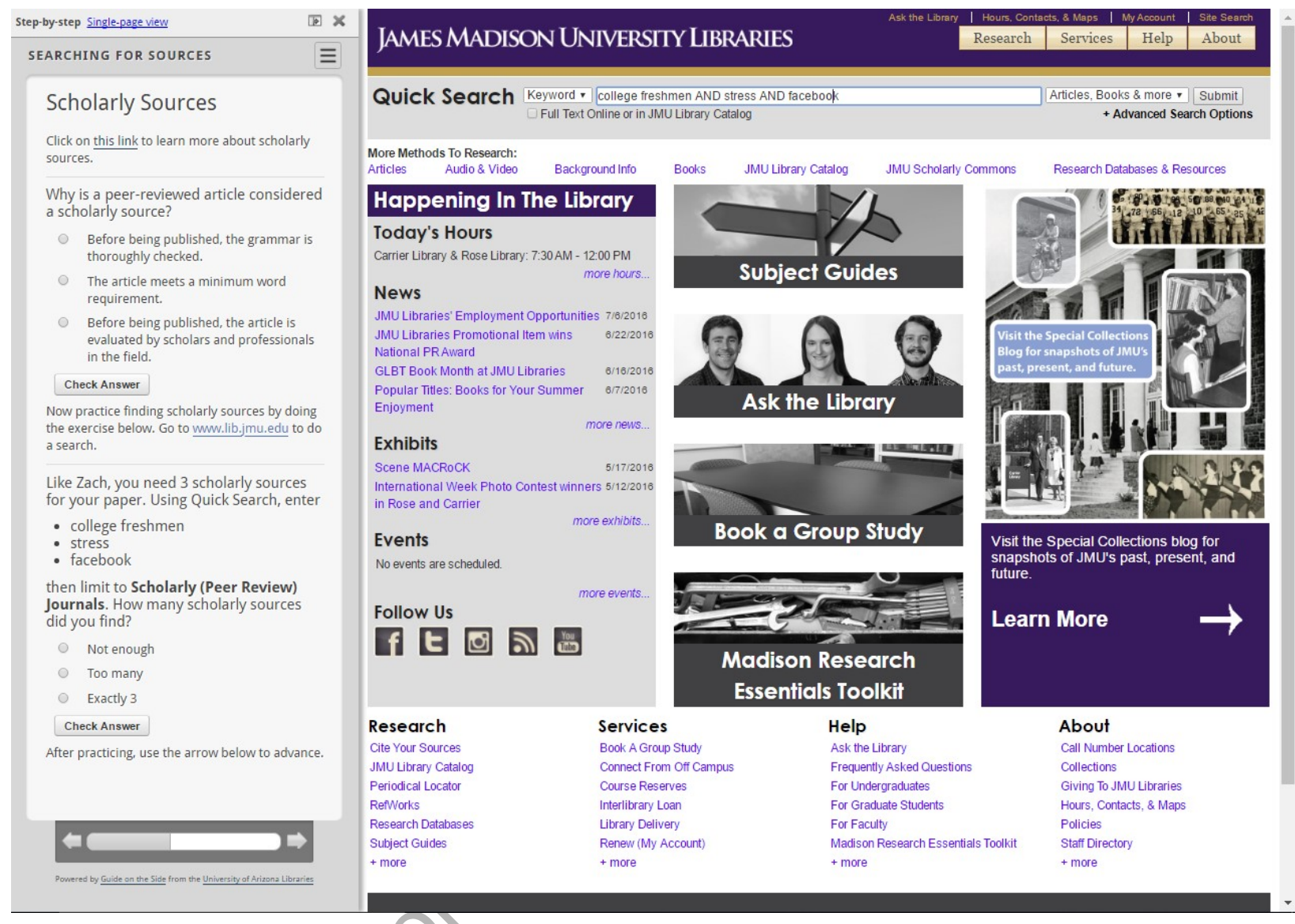


(Image 3. Tutorial formative questions)

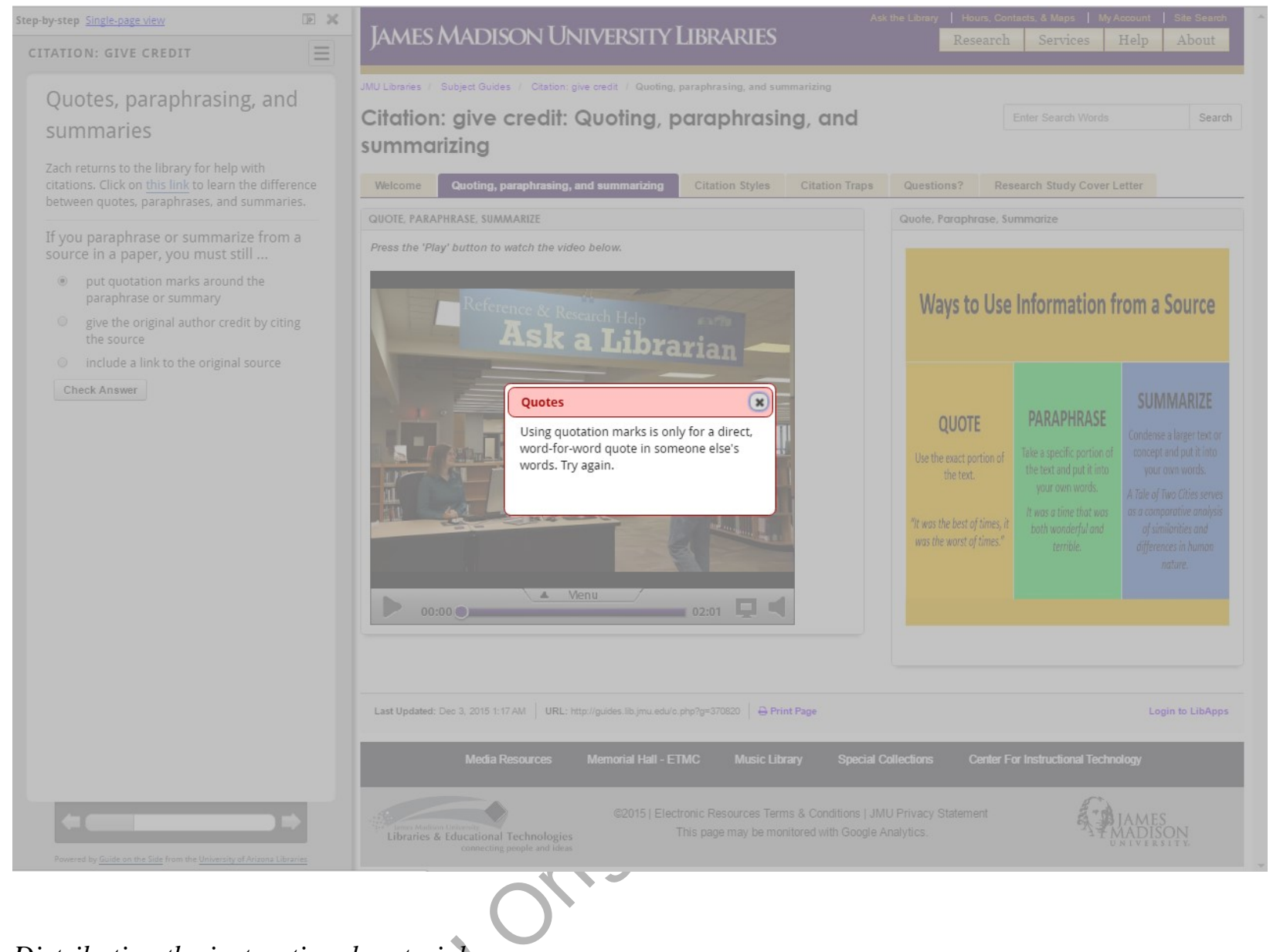

\section{Distributing the instructional materials}

Before the design team started planning the timeline for this project, the WRTC liaison librarian met with the First Year Writing Coordinator about transitioning information literacy instruction from classroom sessions to asynchronous tutorials. The First Year Writing Coordinator managed the more than 40 full-time and adjunct faculty members that taught WRTC 103 and, along with the First Year Writing Committee, they agreed to provide feedback on the tutorials before the fall semester began.

Communication to faculty about the transition in information literacy instruction took place directly with individuals and also with email blasts to all of the WRTC 103 instructors. The liaison also demonstrated the tutorials at faculty meetings and worked with faculty to share the links with students directly via email or as part of the course design in the learning management system.

As faculty contacted the WRTC liaison librarian to schedule classroom-based information literacy sessions or to find out more about the tutorials, the library liaison consulted with the faculty to make sure the tutorials would be a good option for each learning situation. In a few instances, the tutorials 
did not support the assignment or the students' information literacy needs, and the liaison customized classroom sessions for those specific assignments.

\section{Results}

Assessment and evaluation were built into the project from the initial stages of planning. Student assessment and tutorial evaluation fell into three distinct categories:

- Did the tutorial format allow us to reach as many students as face-to-face classroom sessions?

- $\quad$ Did we maintain the attention of the students (motivational design strategy)?

- Did we adequately cover the content to facilitate student learning?

The research team collected data showing visits to the websites and data from the tutorials. Tutorial data included responses to the formative questions in the online activities and responses to the open ended motivational questions at the end of each tutorial. In the Fall semester, 25 students opted to participate and in the Spring semester 38 students participated in the study for a total of 63 students for the 2015/16 academic year.

\section{Number of students reached}

The researchers had access to student attendance numbers for prior year in-class instruction sessions. In order to create a close approximation to similar data in the asynchronous environment, the researchers collected website hits from the private LibGuide homepages used in the tutorials. In the asynchronous tutorial pilot year, the number of students reached appears to be slightly lower than the face-to-face instruction sessions from previous semesters (see Table 2).

(Table 2. Number of students reached by library instruction sessions)

\begin{tabular}{|l|c|l|}
\hline Semester & Students Reached & Session \\
\hline 2014 Spring & 251 & In class \\
\hline 2014 Fall & 552 & In class \\
\hline 2015 Spring & 368 & In class \\
\hline 2015 Fall & 471 & Tutorial \\
\hline 2016 Spring & 341 & Tutorial \\
\hline
\end{tabular}


The goal was to reach as many WRTC 103 students with the asynchronous tutorials as the WRTC librarian had reached the previous year with in-class instruction sessions. The numbers, although lower for the asynchronous tutorials, were still close enough to the previous year to be encouraging.

\section{Keeping student attention}

To determine student motivation, the researchers adapted questions from Keller's (2010) Instructional Materials Motivation Survey (IMMS), and those questions appeared at the end of each tutorial along with the IRB statement. The researchers adapted two attention-related questions and two relevance-related questions from the IMMS for use in the tutorials (see Appendix A). The questions that related to student attention were:

- This tutorial was boring.

- $\quad$ The tutorial format helped keep my attention.

As per the IRB approval, the reported data came from students who agreed to submit their responses for use in the research study. Of the students that opted in to the study, slightly less than half (41\%) responded to the motivation questions at the end of the tutorials. Of those who responded to the motivation questions, an overwhelming 95\% stated "Yes" in response to the statement "The tutorial format helped keep my attention.” The statement "This tutorial was boring” received a "No" response from slightly more than half (55\%) of the respondents. These responses seem to indicate that the tutorials kept student attention, but that there is room for improvement.

\section{Content was understood}

Throughout the tutorials, students answered formative questions to check their understanding of critical topics. Each tutorial had three to five formative questions, and students received an immediate response to their answers. If a student gave an incorrect answer, a box opened with an explanation about why it was wrong, and they were prompted to try to answer the question correctly. Students could attempt to answer a question as many times as necessary to understand the concept. The data from the formative question results are shown in Table 3. 
(Table 3. Results of formative tutorial questions)

\begin{tabular}{|l|l|l|}
\hline Tutorial title & Correct & Incorrect \\
\hline Topic selection & $96 \%$ & $4 \%$ \\
\hline Searching for information & $99 \%$ & $1 \%$ \\
\hline Citing sources & $99 \%$ & $1 \%$ \\
\hline
\end{tabular}

\section{Discussion}

In light of the pilot year and the researchers' and designers' experiences, the authors have identified limiting factors and considerations that impacted this project. The design process was hindered by limited time and resources. The instructional design team wanted to script and record full-action videos to enhance the connections students had to the tutorials through the story with the intent to create a stronger feeling of relevance. The design team settled for using still photos in the videos and have no way to measure the impact this decision had on the relevance factor. The decision to use GotS for the tutorials caused several authentication issues. Changes to wireless hosting on-campus and the email system resulted in an unexpectedly large number of troubleshooting communications during the first semester, which might have caused some faculty to postpone implementing the new tutorials. Statistically, the number of students that received in-class instruction during the 2014-2015 academic year does not align directly with the number of hits to the LibGuide homepages for each tutorial. Due to the tutorials asynchronous nature, students may have started the same tutorial multiple times before completing it. Unlike the in-class instruction sessions, researchers cannot definitively state how many unique, individual students completed each tutorial. With regards to research design, the small sample size was a result of the opt in nature of the IRB approval for this study. The high percentage of correct answers to the tutorial questions was directly attributable to the questions being formative. While the high percentage of correct answers shows students used the questions to improve their understanding of the concepts, the researchers do not know how many attempts each student made to arrive at the correct answer.

\section{Conclusions}

Building on this set of tutorials, the instructional design team and the researchers see opportunities for improvement and growth. Future goals for this asynchronous instruction model include increased impact, improved design, and adding new topics to the series. The design team is considering 
additional outreach to faculty in the department and redesigning the story for the videos to increase impact and reach more students. The design team is also considering other improvements including moving the tutorials from GotS to LibWizard if this move would reduce the number of authenticationrelated issues. The liaison librarian received constructive comments from WRTC faculty and is currently addressing those comments.

The researchers began with the premise: Scalable equals asynchronous. And asynchronous equals boring. Or does it?. This study, although limited, suggests that JMU students did find the materials engaging. The tutorials met the primary objective, which was to create scalable, asynchronous instruction materials that students would actually use.

\section{Acknowledgements}

Thanks to Bethany Mickel for her invaluable contributions - without which this project would not have been possible.

\section{References}

Association of College and Research Libraries (2016). Framework for information literacy for higher education. Retrieved from http://www.ala.org/acrl/standards/ilframework

Branch, R.M. (2008). Instructional Design: The ADDIE approach. New York: Springer.

Dennis, M. \& Dees, A. (2015). It's SO Boring: Improving Library Orientation Sessions For First-Year Students. Southeastern Librarian, 63(2), 2-10.

Gustavson, A., Whitehurst, A., \& Hisle, D. (2011). Laying the information literacy foundation: a multiple-media solution. Library Hi Tech, 29(4), 725-740.

James Madison University (n.d.). General Education: Cluster One. Retrieved from https://www.jmu.edu/gened/Cluster\%20One\%20Requirements.shtml

Keller, J. M. (2010). Motivational Design for Learning and Performance: The ARCS model approach. New York: Springer

Mikkelsen, S., \& McMunn-Tetangco, E. (2014). Guide on the Side: Testing the Tool and the Tutorials. Internet Reference Services Quarterly, 19(3/4), 271-282.

University of Arizona Libraries (2016). Guide on the Side. Retrieved from http://code.library.arizona.edu/ 


\section{Appendix A}

Screen-capture of the primary data collection instrument.

\section{Help make this tutorial better}

We appreciate your comments.

This tutorial was boring.

Yes/No + comments

The tutorial format helped keep my attention.

Yes/No + comments

I already knew most of what the tutorial covered.

Yes/No + comments (what did you already know?)

What I learned in this tutorial will be useful to me.

Yes/No + comments

If you did this tutorial as part of course assignment, click this link to complete the brief review and receive credit.

Now use the arrow below to complete this tutorial. 